\title{
The relationship of plasma levels of pyridostigmine to clinical effect in patients with myasthenia gravis
}

\author{
SC DAVISON,* NM HYMAN,* A DEHGHAN, $\dagger \mathrm{K} \mathrm{CHAN \dagger}$ \\ From the Department of Neurology, Radcliffe Infirmary, Oxford, ${ }^{*}$ and the School of Pharmacy, Liverpool \\ Polytechnic, Liverpool ${ }^{\dagger}$
}

SUMMARY The relationship between plasma levels of pyridostigmine to clinical evaluation of muscle power was examined in nine patients with myasthenia gravis during treatment with pyridostigmine in doses of 60 to $1040 \mathrm{mg}$ daily. Five of the nine subjects demonstrated a trend towards a positive correlation, but in only two of them was this statistically significant at $p<0.05$. In addition, the presence or absence of a possible correlation between muscle power and plasma concentration was not related to the duration of the disease, additional prednisolone therapy or thymectomy.

Although anti-cholinesterases have been used in the treatment of myasthenia gravis since 1935, only recently has a reliable method been developed for measuring plasma concentrations of those drugs most commonly used. ${ }^{12}$ The present study was undertaken to examine the relationship between plasma levels of pyridostigmine and a global clinical evaluation of muscle power and fatigability such as could be carried out during an outpatient consultation. The discovery of a positive correlation between a global assessment of muscle power and plasma levels of pyridostigmine would be a valuable aid in optimising dosage schedules in individual patients.

\section{Patients and methods}

Two male and seven female patients between the ages of 19 and 58 years with histories of myasthenia gravis of 2 to 22 years duration were studied. Five of them had had thymectomies and three were being treated with prednisolone on alternate days. Histological examination of the thymus glands which were removed showed hyperplasia in four and thymoma in the fifth. The total daily dose of pyridostigmine ranged from 60-1080 mg. A diagnosis of myasthenia gravis was made if two of the following criteria were fulfilled: (a) a characteristic electromyographic response, ${ }^{3}$ (b) a positive edrophonium test, ${ }^{4}$ (c) an excess over normal of autoantibody directed against human skeletal muscle acetyl choline receptors. ${ }^{5}$ None of the subjects were severely disabled by the disease and informed consent was obtained. Patients were

Address for reprint requests: Dr N Hyman, The Radcliffe Infirmary, Oxford, UK.

Received 23 January 1981 and in revised form 10 August 1981 Accepted 28 August 1981 admitted to hospital for a period of 24 hours and maintained on their normal drug regime during that time. All subjects rehearsed a routine of tests, summarised in table 1 , designed to measure muscle power and susceptibility to fatigue. The routine took a maximum of 20 minutes to complete, any individual test being terminated after two minutes if no fatigue occurred, and it was performed immediately before each blood sample was taken. A schedule of testing and blood sampling was devised for each patient with the explicit intent of choosing the times of day that each patient normally experienced maximum and minimum fatigue. In addition, sampling times were chosen in relation to the previous dose of pyridostigmine to preserve comparability between the three morning and the three afternoon tests. For example. a patient taking $60 \mathrm{mg}$ of pyridsotigmine at three hourly intervals throughout the day starting at 7.00 am would have blood samples taken at $8.00(1 \mathrm{hr}) 10.00(3 \mathrm{hr})$ $12.00(2 \mathrm{hr}) 16.00(3 \mathrm{hr}) 18.00(2 \mathrm{hr})$ and $20.00(1 \mathrm{hr})$; hours after preceding oral dose are in parentheses. Immediately after the blood sample was taken it was mixed with lithium heparin and the plasma separated by centrifugation. It was rapidly frozen and stored at $-20^{\circ} \mathrm{C}$. The concentration of pyridostigmine was subsequently measured in duplicate by gas liquid chromatography. A small quantity of plasma was set aside to measure in triplicate the concentration of acetyl choline receptor antibody according to the method of Lindstrom, ${ }^{5}$ using acetyl choline receptors prepared from human calf muscle labelled with ${ }^{125} \mathrm{I}$ bungarotoxin as the antigen.

\section{Results}

Table 2 summarises the daily dose and plasma concentration range of pyridostigmine, the concentration of autoantibody to skeletal muscle acetyl 
Table 1 The routine of tests of muscle power and fatigue used to arrive at a global clinical measure of muscle functions. A stop watch was used for the time tests

\begin{tabular}{|c|c|c|}
\hline Instruction to subject & End point & Comment \\
\hline $\begin{array}{l}1 \text { Look straight ahead and fix your gaze on } \\
\text { an object at eye level }\end{array}$ & $\begin{array}{l}\text { The widest part of the palpebral fissure was } \\
\text { measured using a transparent rule } \\
\text { calibrated in } \mathrm{mm}\end{array}$ & $\begin{array}{l}14-16 \mathrm{~mm} \text {. This test is very sensitive to the } \\
\text { position of the head in space. Care must be } \\
\text { taken to reproduce it exactly for valid } \\
\text { comparisons }\end{array}$ \\
\hline $\begin{array}{l}2 \text { While facing forward fix your gaze on a } \\
\text { landmark on the ceiling; tell me when you } \\
\text { begin to see double or cannot see it any more }\end{array}$ & Diplopia or loss of fixation (time in s) & $\begin{array}{l}25-120 \mathrm{~s} \text {. Despite depending on the } \\
\text { subjective report of the patient, the end point } \\
\text { develops rapidly and is easily recognised }\end{array}$ \\
\hline $\begin{array}{l}3 \text { Hold both your arms out horizontally in } \\
\text { front of you } \\
4 \text { Grip this ballon as tightly as you can and } \\
\text { keep squeezing it hard }\end{array}$ & $\begin{array}{l}\text { When the hands drop below a horizontal line } \\
\text { drawn from the shoulder (time in s) } \\
\text { When the pressure registered on the } \\
\text { manometer drops to one half of the pressure } \\
\text { registered initially. Each hand is tested in } \\
\text { turn (time in s) }\end{array}$ & $\begin{array}{l}3 \text { Ignore wavering if hands can be brought } \\
\text { back to horizontal position } \\
4 \text { None }\end{array}$ \\
\hline $\begin{array}{l}5 \text { Take the biggest breath you can, then blow } \\
\text { it out through this tube (spirometer) }\end{array}$ & The best of 3 tried measured in $\mathrm{ml}$ & $\begin{array}{l}5 \text { This is a good test providing the subject } \\
\text { can make an airtight seal with her lips }\end{array}$ \\
\hline $\begin{array}{l}6 \text { Lie on your back and raise one leg in the } \\
\text { air to touch my hand, keep it there for as long } \\
\text { as you can }\end{array}$ & $\begin{array}{l}\text { When the leg drops back on to the couch } \\
\text { from an angle of } 45^{\circ} \text { to the horizontal; each } \\
\text { leg is tested in turn (time in s) }\end{array}$ & \\
\hline $\begin{array}{l}7 \text { While lying on your back raise your head } \\
\text { off the bed and hold it unsupported for as long } \\
\text { as possible }\end{array}$ & $\begin{array}{l}\text { When the occiput touches the couch (time } \\
\text { in s) }\end{array}$ & $\begin{array}{l}\text { These are all sensitive and reliable } \\
\text { tests }\end{array}$ \\
\hline $\begin{array}{l}8 \text { Walk a distance of } 75 \text { yrds as fast as you } \\
\text { can }\end{array}$ & The distance is marked out (time in s) & 8 \\
\hline
\end{tabular}

Table 2 Duration of disease, daily dose and plasma concentration of pyridostigmine and concentration of AChR-SM.

\begin{tabular}{|c|c|c|c|c|}
\hline Subject & Duration of disease $(y r)$ & $\begin{array}{l}\text { Total daily dose of pyridostigmine in } \\
\mathrm{mg} / \mathrm{kg}\end{array}$ & $\begin{array}{l}\text { Range of plasma concentration of } \\
\text { pyridostigmine } n g / \mathrm{ml}\end{array}$ & $*$ \\
\hline 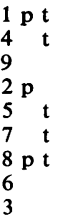 & $\begin{array}{r}2 \\
3 \\
3 \\
7 \\
7 \\
7 \\
11 \\
13 \\
22\end{array}$ & $\begin{array}{r}1 \cdot 07 \\
5 \cdot 26 \\
3 \cdot 87 \\
6 \cdot 55 \\
10 \cdot 19 \\
6 \cdot 11 \\
12 \cdot 03 \\
5 \cdot 71 \\
2.90\end{array}$ & $\begin{array}{r}1 \cdot 3-12 \cdot 4 \\
11 \cdot 0-40 \cdot 0 \\
6 \cdot 2-25 \cdot 0 \\
9 \cdot 0-36 \cdot 0 \\
20 \cdot 5-64 \cdot 5 \\
24 \cdot 0-39 \cdot 0 \\
11 \cdot 0-36 \cdot 5 \\
25 \cdot 0-40 \cdot 0 \\
5 \cdot 0-14 \cdot 0\end{array}$ & $\begin{array}{r}685 \\
316 \\
10 \\
770 \\
4370 \\
1645 \\
2620 \\
40 \\
4690\end{array}$ \\
\hline
\end{tabular}

*Autoantibody to AChR-SM. Mol/1 × $10^{10}$.

p Subjects taking prednisolone on alternate days.

$t$ Subjects undergone thymectomy.

choline receptor (AChR-SM) and the duration of the disease for each subject. There was no evident relationship between the duration of disease, thymectomy or steroid administration and antibody to AChR-SM or pyridostigmine dosage or plasma level. The timing of peak plasma levels of pyridostigmine varied among subjects, although in twothirds of the subjects average plasma levels were higher in the morning (table 4). Examples of the plasma pyridostigmine concentration time curves in relation to oral doses of pyridostigmine are shown in fig 1 . The variation is not surprising given the differences in dosage schedule. The clinical assessment of individual motor functions (table 1) was scored as follows: for each subject, each separate exercise testing a particular function was evaluated across all six trials in two ways. They were ranked 0-5 from worst to best performance and they were also rated on a continuous scale with worst and best set to 0 and 10 respectively. Each separate test routine was then given both a rank score and a scale score by taking the mean of the different subtests. The idealised example set out in table 3 will clarify this. Absolute values could not be used because of the difficulty of arriving at a composite score from different units of measurements. Each subject acts as their own control. Both mean rank and mean scale scores were plotted against plasma concentration of pyridostigmine in $\mathrm{ng} / \mathrm{ml}$ (figs 2,3 ). Regression analysis showed a trend towards a positive correlation between a global assessment of muscle power and plasma pyridostigmine concentration in five of the nine subjects but in only two of them was this significant at $p<0.05$. Of the remaining four one showed a negative correlation at $p<0 \cdot 1$; the findings are summarised in table 5. Variation in disability between subjects was considerable in spite of the fact that from a simple questionnaire 

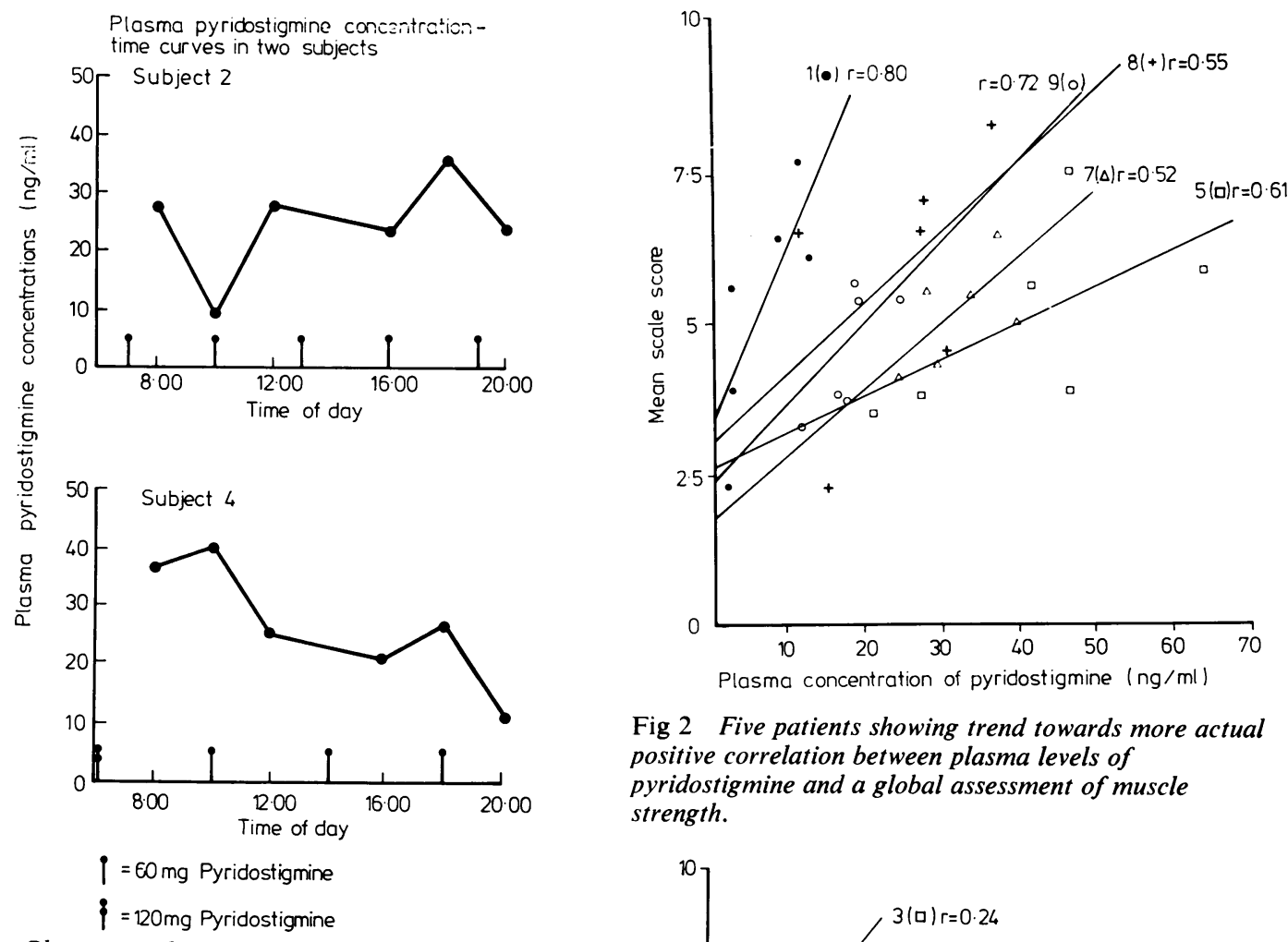

Fig 2 Five patients showing trend towards more actual positive correlation between plasma levels of pyridostigmine and a global assessment of muscle strength.

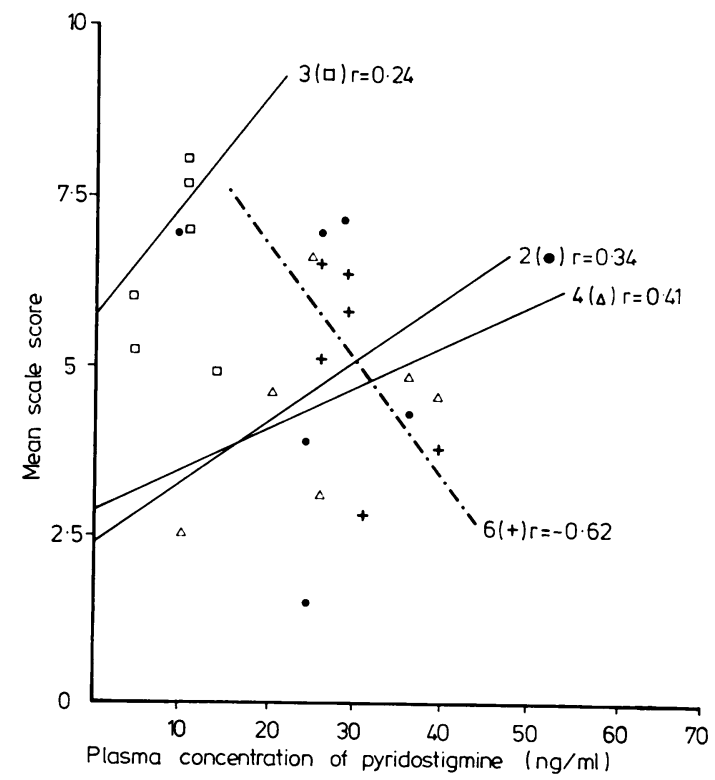

Fig 1 Plasma pyridostigmine concentration-time curves in two subjects.

Table 3 Time of day

\begin{tabular}{lllllll}
\hline Function & 8.00 & 10.00 & 12.00 & 16.00 & 18.00 & 20.00 \\
\hline Vital & & & & & & \\
capacity (ml) & 1850 & 1950 & 2100 & 1900 & 1950 & 2000 \\
Rank & 0 & $2 \cdot 5$ & 5 & 1 & $2 \cdot 5$ & 4 \\
Scale & 0 & 4 & 10 & 2 & 4 & 6 \\
\hline
\end{tabular}

Table 4 The diurnal variation in plasma concentration of pyridostigmine and performance in the test routine, the averages of the three measured before and after noon are compared

\begin{tabular}{|c|c|c|c|c|}
\hline \multirow[t]{2}{*}{ Subject } & \multicolumn{2}{|c|}{$\begin{array}{l}\text { Plasma pyridostigmine } \\
\text { concentration (average) } \\
n g / m l\end{array}$} & \multicolumn{2}{|c|}{ Mean scale score } \\
\hline & Before noon & After noon & Before noon & After noon \\
\hline 1 & $10.7 \mathrm{ng} / \mathrm{ml}$ & $1.5 \mathrm{ng} / \mathrm{ml}$ & $6 \cdot 7$ & 3.9 \\
\hline 2 & 21 & 28 & $5 \cdot 8$ & $3 \cdot 3$ \\
\hline 3 & 12 & 7 & $6 \cdot 8$ & $6 \cdot 0$ \\
\hline 4 & $33 \cdot 7$ & $19 \cdot 7$ & $5 \cdot 3$ & $3 \cdot 3$ \\
\hline 5 & $44 \cdot 6$ & $37 \cdot 5$ & $5 \cdot 7$ & $4 \cdot 4$ \\
\hline 6 & $28 \cdot 2$ & $31 \cdot 8$ & $5 \cdot 7$ & $4 \cdot 5$ \\
\hline 7 & $33 \cdot 2$ & $29 \cdot 7$ & $5 \cdot 3$ & $5 \cdot 1$ \\
\hline 8 & $17 \cdot 5$ & $31 \cdot 2$ & $5 \cdot 2$ & $6 \cdot 5$ \\
\hline 9 & 20 & $16 \cdot 6$ & $5 \cdot 5$ & $3 \cdot 4$ \\
\hline
\end{tabular}

Fig 3 Four patients showing low or negative correlation between plasma levels of pyridostigmine and a global assessment of muscle strength.

with respect to the degree of disability each subject experienced in their daily life no significant differences were noted. 
Table 5 The correlation of plasma levels of pyridostigmine with performance in the test routine scored both by ranking and by using a scale

\begin{tabular}{lccl}
\hline \multirow{2}{*}{$\begin{array}{l}\text { Subject } \\
\end{array}$} & \multicolumn{2}{l}{ Correlation coefficients } & $\begin{array}{l}\text { Significance } \\
p, \text { for scale score }\end{array}$ \\
\cline { 2 - 3 } & Rank score & Scale score & \\
\hline 1 & 0.76 & 0.80 & 0.025 \\
2 & 0.35 & 0.34 & 0.35 \\
3 & 0.27 & 0.24 & 0.354 \\
4 & 0.35 & 0.41 & 0.025 \\
5 & 0.64 & 0.61 & 0.001 \\
6 & -0.78 & -0.62 & 0.001 \\
7 & 0.54 & 0.58 & 0.015 \\
8 & 0.41 & 0.55 & 0.015 \\
9 & 0.9 & 0.72 & 0.005 \\
\hline
\end{tabular}

Some tests were not useful in some patients because they registered no change or no fatigue. However the importance in using all the subtests became clear when we noted that some functions fatigued maximally at different times from others. For example, in one subject the vital capacity might be at its lowest mid-morning, whereas walking 75 yards $(68 \mathrm{~m})$ was slowest in the evening and the arms fatigued most rapidly at noon. Nevertheless there was a tendency for good performances and poor performances to segregate so that the cumulative picture measured by the mean rank and mean scale scores was more representative of the subject's status than any single function. No single test correlated with plasma pyridostigmine concentration more closely than the global assessment. Diurnal variation in global scores for muscle strength was observed in all subjects except No 7 (table 4) and only one (No 8) was stronger in the afternoon than in the morning. This corresponds well with the patients' subjective observations. In only two subjects ( 2 and 6 ) was greater average muscle fatigue associated with higher average levels of plasma pyridostigmine. Subject 6 also showed a negative correlation $\mathrm{p}<0.1$ between muscle strength and plasma pyridostigmine plotted individually (fig 2). One possible explanation for this observation is that this patient was receiving excessive medication. She was, however, particularly difficult to assess as her myasthenic disease included her extraocular muscles whereas her limb symptoms were thought to be functional.

\section{Discussion}

Studies of blood levels in myasthenia gravis are required since alteration of doses of oral anticholinesterases depends largely on the patient's own subjective response. The edrophonium test ${ }^{4}$ to determine optimal dosage is frequently difficult to interpret because the effect varies at different times in the same day and on other occasions it may improve function of some muscles but either does not alter or worsens the strength in others. ${ }^{6}$

It might therefore be predicted that similar difficulties would be encountered with the interpretation of serum levels when correlated to clinical signs. In addition, the pharmacokinetics of pyridostigmine are poorly understood and there is no good reason to predict that such a correlation should exist. Nevertheless, some previous studies suggest that a relationship between serum level and response may exist. In one such trial ${ }^{7}$ nine myasthenic patients were examined at 30 minute intervals for 6 hours after drug administration and improved motor strength subjectively was apparently paralleled by serum pyridostigmine concentrations but the authors felt that the clinical response was not quantifiable. In another study ${ }^{8}$ wide variations in the oral dosage (60 to $660 \mathrm{mg}$ ) nevertheless produced a relatively narrow plasma pyridostigmine range $(20$ to $60 \mathrm{mg} / \mathrm{nl})$. In an earlier study ${ }^{9}$ four patients with unsatisfactory control had lower serum levels than those who were well controlled. The strength of these patients improved when the serum pyridostigmine level was increased by intravenous administration of pyridostigmine and they demonstrated that the original low levels were due to malabsorption. A further type of correlation was made on $\frac{\stackrel{\rho}{\mathbb{D}}}{\circ}$ four patients with typical electromyographic decre- $\frac{2}{2}$ ments in adductor pollicis consistent with myasthenia gravis. ${ }^{10}$ There was positive correlation 8 between the concentration of pyridostigmine in plasma and the effect of the drug on neuro-muscularo transmission. In the present series of nine patients? a wide variety of exercises each testing particular functions was thought important due to possible variations in the strength of different muscle groups in the same patient; in addition, the clinical responses were quantified satisfactorily. In only two subjects was there a significant correlation between muscle power and plasma concentration. No single test of motor function correlated more closely with plasma drug level than the global assessment. In addition, the presence or absence of a possible correlation between muscle power and plasma concentration was not apparently related to the duration of the disease, additional prednisolone therapy or thymectomy.

SD wishes to thank Professor WB Matthews for arranging financial support for the project from University funds. $\mathrm{KC}$ is grateful to the MRC for supporting his research. Thanks are also due to Professor M Gelder, Department of Psychiatry, Oxford University and his colleagues for the loan of laboratory space and equipment and we are 
grateful to Professor WB Matthews and Dr C Davis for allowing us to study their patients.

\section{References}

' Chan K, Williams NE, Baty JD, Calvey TN. A quantitative gas-liquid chromatographic method for the determination of neostigmine and pyridostigmine in human plasma. $J$ Chromatogr 1976;120: 349-58.

2' Davison SC, Hyman NM, Prentis RA, Dehghan A, Chan K. The simultaneous monitoring of plasma levels of neostigmine and pyridostigmine in man, Meth and Find. Exp Clin Pharmacol 1980;2(2): 77-82.

${ }^{3}$ Grob D, Namba T. Characteristics and mechanism of neuromuscular block in myasthenia gravis. Ann $N Y$ Acad Sci 1976;274:143-73.

* Osserman KE. Myasthenia Gravis. New York: Grune and Stratton, 1958:155-158, 169.

5 Lindstrom J. An assay for antibodies to human acetyl choline receptor in serum from patients with myasthenia gravis. Clin Immunol Immunopathol $1977 ; 7: 36-43$.

${ }^{6} \mathrm{King}$ Engel W. Myasthenia gravis, corticosteroids, anticholinesterases. Ann NY Acad Sci 1976;274: 623-30.

' Cohan SL, Pohlmann JLW, Mikszweski J, O'Doherty D. The pharmacokinetics of pyridostigmine. Neurology (Minneap) 1976;26:536-9.

${ }^{8}$ Calvey TN, Chan K. Plasma pyridostigmine levels in patients with myasthenia gravis. Clin Pharm Therap 1977;21 :187-93.

9 Cohan SL, Dretchen KL, Neal A. Malabsorption of pyridostigmine in patients with myasthenia gravis. Neurology (Minneap) 1977;27:299-301.

${ }^{10}$ Chan K, Calvey TN. Plasma concentration of pyridostigmine and effects in myasthenia gravis. Clin Pharm Therap 1978;22:596-601. 